\title{
Correction to: Adult spinal deformity surgery: the effect of surgical start time on patient outcomes and cost of care
}

\author{
William H. Shuman ${ }^{1}$ (D) . Sean N. Neifert ${ }^{1}$. Jonathan S. Gal ${ }^{2}$. Michael L. Martini ${ }^{1}$ - Alexander J. Schupper ${ }^{1}$. \\ Jeremy M. Steinberger ${ }^{1}$ - Samuel Z. Maron ${ }^{1} \cdot$ Colin D. Lamb $^{1} \cdot$ Robert J. Rothrock $^{1} \cdot$ Ian T. McNeill ${ }^{1}$. Samuel K. Cho ${ }^{1,3}$. \\ John M. Caridi ${ }^{1}$
}

Published online: 18 May 2020

(c) Scoliosis Research Society 2020

\section{Correction to: Spine Deformity}

https://doi.org/10.1007/s43390-020-00129-x

The original version of this article unfortunately contained a mistake. The first name of the author "Samuel Z. Maron" was incorrectly provided as "Sam" instead of "Samuel".

The original article has been corrected.

Publisher's Note Springer Nature remains neutral with regard to jurisdictional claims in published maps and institutional affiliations.

The original article can be found online at https://doi.org/10.1007/ s43390-020-00129-x.

William H. Shuman

will.shuman@icahn.mssm.edu

1 Department of Neurosurgery, Icahn School of Medicine at Mount Sinai, 50 East 98th St, Apartment 7D-4, New York, NY 10029, USA

2 Department of Anesthesiology, Icahn School of Medicine at Mount Sinai, New York, NY, USA

3 Department of Orthopedic Surgery, Icahn School of Medicine at Mount Sinai, New York, NY, USA 